\title{
Impact of Technology on Safety as Viewed by Ship Operators
}

\section{Darijo Miškovića, Toni Bielićc ${ }^{b}$ Jelena Čulin ${ }^{b}$}

Modern technology is being increasingly used on-board ships. It is a common opinion that its application has reduced seafarers' workload and improved safety of ships. However, human error induced by technology contributes significantly to risk in shipping. This paper analyses human and machine interaction and demonstrates which elements violate these connections. It is for this purpose that the survey has been conducted via an anonymous questionnaire among professional seafarers. The results indicate that non-standardisation of equipment, i.e. the differences in the settings and display interfaces between different manufacturers and poor design prolong time needed for familiarisation, and in combination with short period of handover can contribute to the occurrence of human error. Greater involvement of the ship operators in the procurement process of navigation equipment is essential, since it may lead to the selection of equipment that suits the end users.

\section{KEY WORDS}

$\sim$ Marine accidents

$\sim$ Human error

$\sim$ Human-machine interaction

$\sim$ Equipment standardisation

$\sim$ Type-specific training a. Maritime Department, University of Dubrovnik, Dubrovnik, Croatia

e-mail: darijo.miskovic@unidu.hr

b. Maritime Department, University of Zadar, Zadar, Croatia

doi: 10.7225/toms.v07.n01.005

This work is licensed under (cc) BY

\section{INTRODUCTION}

In terms of tools and technology, ship's management has changed tremendously during the last few decades, by introducing larger ships at greater speed, increased number of passengers and volume of cargo, as well as the increased level of automation. Technological developments and improved safety standards were expected to affirm overall human capacity and diminish the occurrence of human error (Turan et al., 2016). However, the statistics on maritime accidents has indicated that the system is not resilient to human errors (Ćorović and Djurović, 2013). For example, analyses have shown that human error has been the cause of $67 \%$ of accidents reported to European Marine Casualty Information Platform (EMCIP) in period from 2011 till 2014 (EMSA, 2015). Among other latent failures contributing to the occurrence of human error, lack of knowledge, inadequate tools and equipment, lack of skill, design, lack of information, as well as inadequately presented information have been recognised.

As another cause of accidents with a share of $24 \%$ equipment failure is stated. Leading contributing factors for equipment failure are: maintenance, inadequate tools and equipment, design, regulatory activities, and work place conditions.

Managing ship safety is fed both by the knowledge about underlying accident factors and general ideas on the managing of companies. For better understanding of operators' contribution to accidents we need to understand that they are placed at the centre of the work system, surrounded by series of elements with which she/he interacts, and each element interacts further with others (Carayon et al., 2015). Efficient usage of technology is one of the key factors for minimising risk, otherwise vessel and cargo loss or damage, along with adverse effects on human and environment can happen.

The aim of our study was to investigate which factors could contribute to dysfunctional interaction between operator 
and technology. For that purpose an anonymous survey was conducted among the Masters and officers of the deck. The paper begins with an overview of ergonomic principles of the integrated bridge system (IBS) design, followed by the influence of technology on human element. The results of the survey and implications for safety follow.

\section{ERGONOMIC PRINCIPLES ON-BOARD VESSELS}

Ergonomics is based on a principle that efficient design supports human performance and that ergonomics, as a scientific discipline, is not restricted to the aesthetic qualities. Ergonomically well-designed operating system or part of the equipment takes advantage of humans' capabilities and attenuates the impact of human limitation. At the same time, it is necessary to insure that the equipment or the system is fully functional, i.e. designed for human use and meets operational requirements (IMO, 2001).

The principles of the bridge design, layout of navigation systems and navigational equipment and procedures are provided by the SOLAS Convention, Chapter V, Article 15 (IMO 2000a). Further guidance for human element considerations, regarding design, layout, and integration of personnel with equipment, systems and interfaces are set according to IACS recommendations (IACS, 2011, 2013). Product designers must integrate all information about operators, tasks, and environment to generate an acceptable design. Therefore, emphasis should be also on cultural and regional influences on personnel's behavioural patterns and expectations. This includes understanding that different cultural meanings with regard to colour exist (Madden et al., 2000). Awareness of the possible physical differences is necessary, so that the design, layout, and orientation of the working environment are adapted for the whole range and combinations of crew members. In case that these factors are not considered, the workplace design may increase the likelihood of human error. Detailed written procedures, additional training, operations and maintenance manuals cannot adequately compensate for human errors induced by inadequate design (IACS, 2011, 2013).

Fulfilling ergonomic requirements (IMO, 2000b) is especially important for integrated bridge system, because it is used as a control centre of the vessel. The IMO defines an integrated bridge system as: "a combination of [technical] systems which are interconnected in order to allow centralised access to sensor information or command/control from workstations, with the aim of increasing safe and efficient ship's management by suitably qualified personnel" (IMO, 1996).

The position of instruments and displays must be carefully planned because all the processes are monitored and controlled from one place. This makes the work easier, but also increases the required level of concentration needed for data analysis. The concept of work, regarding the duties of operator, includes manual control, monitoring, diagnostics of possible failures and repairs. Diagnostics and corrections of alarm system are of highest priority. Wrong system settings can often be the cause of "unnecessary" and "false" alarms. These alarms are recognised as ones that endanger the human-machine interaction the most. The instruction and maintenance manuals are very important for efficient interface running. Furthermore, it is very important to be aware of the limitations, which are typical for each system. Monitoring of instruments must be performed continuously and interference of the operator is required only in the case of a detected system failure. Considering its significance for routine and emergency operations, it is crucial to provide the operator with an operative and easily used human-machine interface (HMI).

Characteristics of effective HMI design:

- Depiction of process status and values as information, not numbers,

- $\quad$ Layout consistent with operator's model of the process,

- Key Performance Indicators as trends,

- No gratuitous information,

- Grey backgrounds, low contrast,

- $\quad$ Very limited use of colour (for alarming)

Characteristics of a poor Human Machine Interface design:

Presentation of raw data as numbers (temperatures, pressures, etc.),

- $\quad$ No trends (representation of the complete process flow),

- Poor interface graphics,

- Bright colours, 3-D shadows (not suitable for night vision),

- colour coding of piping,

- Measurement units in large, bright text,

- Lots of crossing lines,

- Alarm-related colours for non-alarm related elements (Gruhn, 2011).

However, despite the existing requirements and guidelines, an inadequate design of HMI has been identified as one of the factors contributing to adverse situations on- board ships (EMSA, 2015).

To be adequate, the design of technology should correspond to 'work as done' rather than to 'work as imagined'. The challenges to designers come from practical needs which are rapidly changing. Furthermore, ship, as safety-critical system, represents a unique environment. Therefore, the involvement of the operators throughout design and development is necessary. Unfortunately, an insufficient collaboration between designers and operators has been recognised as one of the constraints in the design process (Shorrock and Williams, 2016). 


\section{THE INFLUENCE OF TECHNOLOGY ON THE OPERATORS}

The role of technology on modern vessels is to make planning and problem resolving easier and to enhance safety. The technological advances have led to reduction of physical work, and contributed to decreased manning. However, technology design features can negatively impact two important factors for decision making: decision performance (situation awareness, threat avoidance, voyage plan monitoring) and decision processes (workload, stress, confidence, satisfaction, effort, vigilance and fatigue) (Dhami and Grabowski, 2011; Hetherington et al., 2006).

The increase in automation level changes the role of the seafarer. It detaches the operator from the control process, because the operator is not fully aware of all the relevant information needed for decision making in emergency situations. Furthermore, it is important to stress that the level of automation of working processes on modern vessel systems is high in demand in terms of human information processing. Increased cognitive demands can lead to fatigue and stress and consequently to detriment in performance (IMO, 2001). If the quantity of information is greater than the operator's capacity to process them, it can affect the time needed for decision making and cause a delay in safety-critical decision making.

There is also a risk of relying too much on technological systems instead of on traditional navigational skills. Consequently, seafarers might forget how to cope with dangerous situations if navigation support system is out of use for some reason. Furthermore, over-reliance on technology, lack of understanding of its limitations and overconfidence in the provided data can lead to a false sense of security and wrong perception or understanding of external environment (Schröder-Hinrichs et al., 2012).

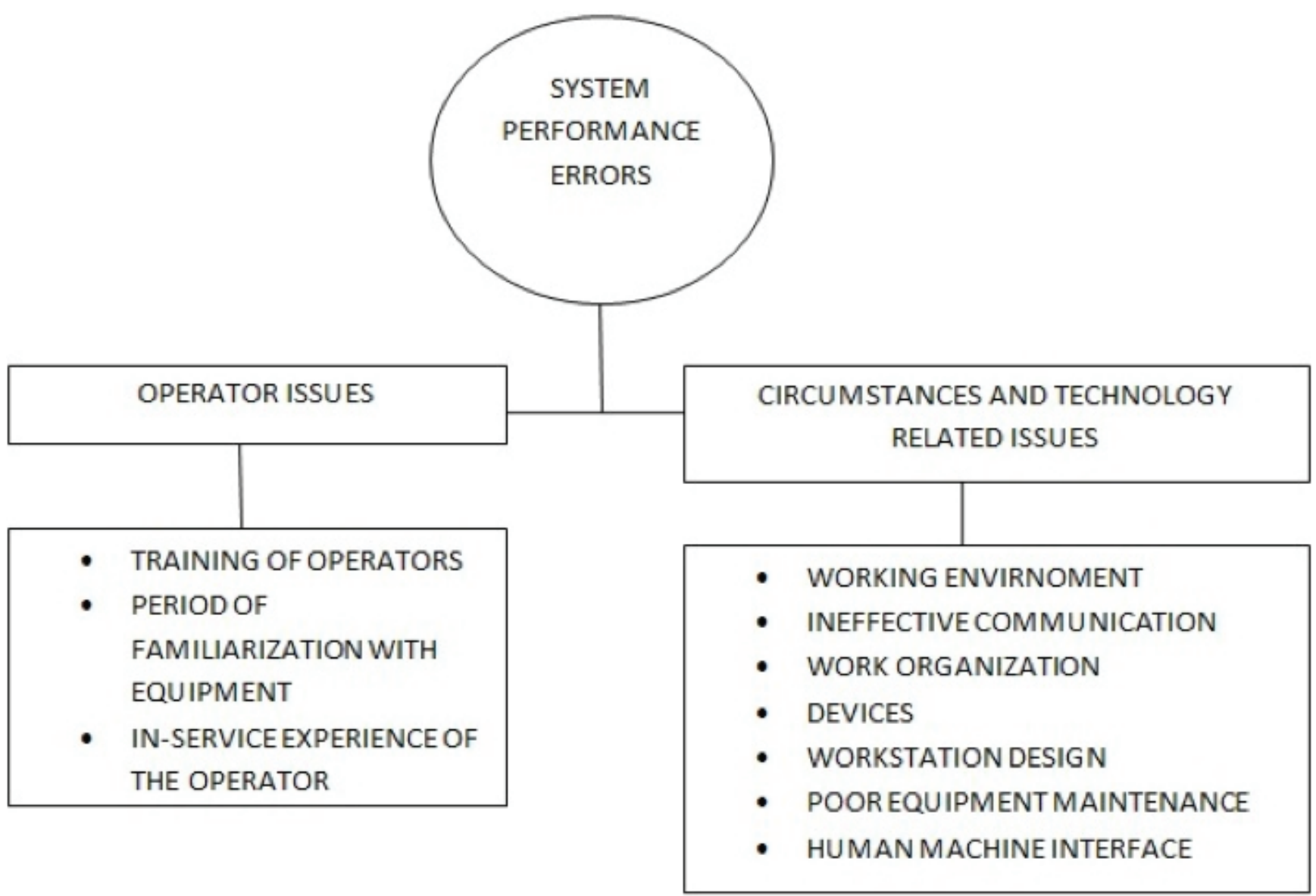

Figure 1.

Graphic representation of elements that might cause system performance error. 
Combination of above mentioned factors might result in some type of system performance error (Figure 1).

Causes of system performance errors can be divided into operator issues and circumstances and technology related issues.

Operator issues are inadequate training, lack of time for familiarising with the equipment and the insufficient previous professional experience of the operator. After signing-on and taking over the duties, operators personal qualities and qualifications for work with the instruments come to expression, and those are directly associated with the period needed to get acquainted with them. Taking into consideration their qualities and required qualifications, a decision on employment is made by the Human Resources Department upon completion of testing and interviews. The training of seafarers on operating a specific system is of a great importance because it is unrealistic to expect that, following a short period of familiarising with the equipment on-board and with the experiences of their colleagues, they will be able to use systems competently. According to STCW Convention training is required for following navigational equipment: Radar/Arpa, Global Maritime Distress and Safety System (GMDSS) - generic training; - Electronic Chart Display Information System (ECDIS) - generic training and familiarisation training for the equipment fitted on-board. Additional training required is according to vessel type (tanker, passenger), which is also generic.

The period a seafarer needs in order to familiarise himself with the vessel, navigation systems and alarm systems on-board is of utmost importance to avoid human errors. In practice this period ranges from few hours to several days, depending on the time of port operations. Another possibility, more favourable for the new crew member and for the whole ship management system, is the willingness of the company to keep the previous operator on-board until the new member of the crew gets acquainted with the system. In practice, such cases are rare.

Circumstances and technology related errors arise from work environment, inadequate communication (between the members of the crew, between the Master and the pilot, vessel and vessel, and vessel and VTS), work organisation (adjusting the teamwork on modern systems), equipment maintenance procedures, and workspace design (navigating bridge). The additional problem is a lack of standardisation (Turan et al., 2016). Namely, although equipment and workspace design are stipulated by the IMO and IACS regulations, there is always a place for variations. Looking at operating consoles, differences are ranging from a "track ball and three buttons" to those who have a "full keyboard" for work. In order to adapt for work the operator needs a certain amount of time, particularly if he encounters it for the first time. A better scenario is if he has already encountered the equipment in the past, because in that case he needs less time for adjustment.

\section{SURVEY RESULTS AND DISCUSSION}

The authors have conducted an anonymous questionnaire survey among seafarers about their experiences with the navigational equipment and its impact on their daily work. The collected data were analysed with the help of analytics software package "Statistica" ver. 13.1., licensed by the Ministry of Science, Education, and Sports. Kruskal-Wallis H Test was used to determine if there are statistically significant differences between variables.

The survey was conducted among participants of the training courses, in accredited institutions, including only deck officers. A total of 55 respondents met the criteria: 8 Masters, 23 Chief Officers, 19 Second Officers, and 5 Third Officers. Out of 55 respondents, $4 \%$ were between 23 and 26 years old, 31 $\%$ respondents were between 27 and 35 years old, $36 \%$ of respondents were between 36 and 41 years old, $25 \%$ were between 42 and 52 years old and $4 \%$ respondents were older than 50 . As regards education respondents reported that 10 of them has high school degree, 24 college, 20 university degree and $1 \mathrm{PhD}$. Reported navigating experience of respondents are of less than 3 years of in-service experience (5.5\%), 4 -7 years (20\%) 8-12 years (32.7\%) and more than 12 years of in-service experience $(41.8 \%)$. With regard to the number of ships they served on, $5 \%$ of respondents have served on less than 3 ships, $16 \%$ have served on 4-7 ships, $24 \%$ of respondents have served on 8-12 ships whereas $55 \%$ have had experience on more than 12 ships.

The questionnaire consisted of questions concerning the time of handover in their companies, the period needed to familiarise for taking over the watch, the procedure of shipping companies in providing equipment, number of navigational equipment (ECDIS, ARPA, AIS) they have had experience with, number of types of IBS they have had experience with, the maintenance procedures of the bridge equipment, quality of the instruction manuals of equipment they operated, whether they have ever been confused by the data on the system display, usefulness of navigation systems during watch and frequency of fatigue while performing their regular tasks on-board.

Seafarers' answers about time of handover in their companies (Figure 2), taking into account answers for required period of familiarisation to be fully acquainted with equipment, indicate that, in some cases, time of handover is not sufficient to become completely capable for executing their duties. Namely, $53 \%$ of respondents have answered that the average time of handover lasts up to 10 hours while $62 \%$ claim that they need more than one day to familiarise themselves with navigational equipment (Figure 3). This leads to conclusion that during certain period the vessel is underway without proper supervision. The period of handover is limited by time and resource constraints. 
However, efficiency-thoroughness trade-offs can lead to accidents. Therefore it is important that sharp end operators communicate with management about this issue.

In order to obtain additional information Spearman rank order correlation was performed (Table1). As can be seen from the values of Spearman rank order correlation coefficients, positive relationships between in-service experience and the period of handover, number of ships sailed, and current rank are observed, as it could be anticipated. Similarly, there is a positive relationship between age and number of ships sailed, current position on-board, level of education and the period of handover. Seafarers with higher rank navigated more ships.

An analysis of the period of handover in dependence of different variables has shown that second officers report statistically significantly shorter time of handover of the Master and Chief Officer. This result is expected, considering their duties and responsibilities on-board.

An analysis of the relationship between length of familiarisation with the navigational equipment with different variables show that there are no statistically significant differences in the length of familiarisation with regard to the length of the sea service, level of education, current position on-board and with regard to the number of ships sailed. Therefore, based on data obtained in this study it could be concluded that operator's general knowledge and experience are not that much important as quality and number of different types of equipment. However, a more comprehensive research is needed to increase reliability and validity of our findings, and to get a more accurate picture of these relationships.

The fact that only $55 \%$ of respondents have answered that shipping company always uses the same manufacturer

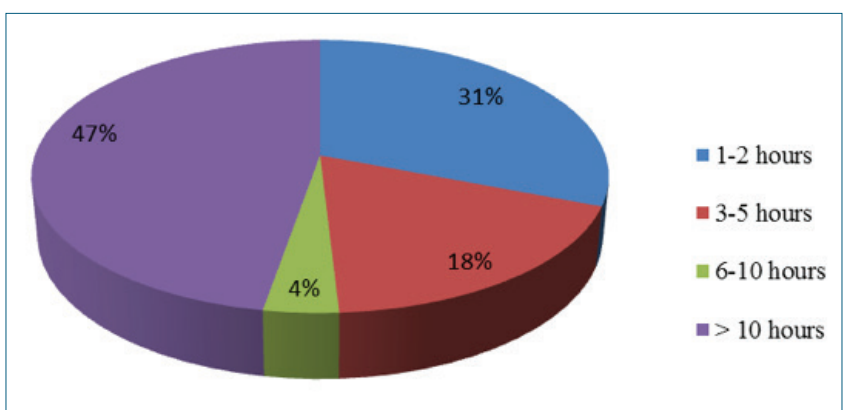

Figure 2.

Answers of respondents on average time of handover in their companies.

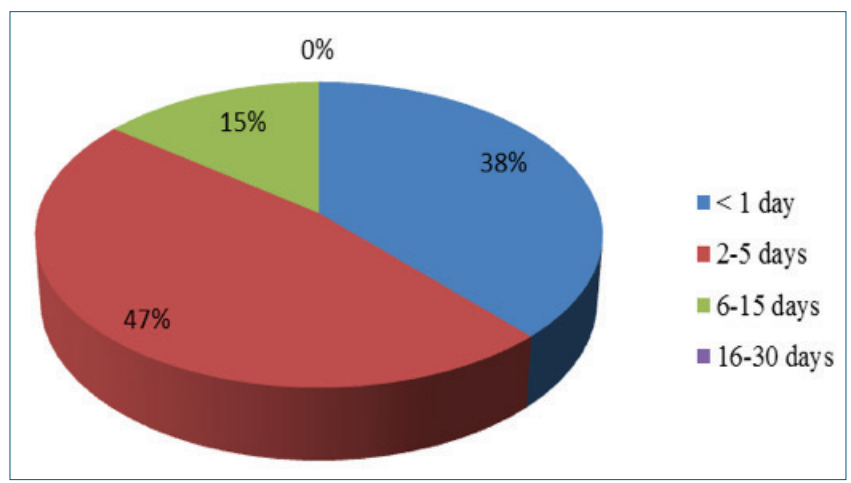

Figure 3.

Answers of respondents on required familiarisation period to be fully acquainted with navigational equipment for taking over the watch.

Table 1.

Relationship between different variables in research.

\begin{tabular}{|c|c|c|c|c|c|c|c|c|}
\hline \multirow[b]{2}{*}{ VARIABLE } & \multicolumn{8}{|c|}{ Spearman Rank Order Correlations Coefficients } \\
\hline & Handover & $\begin{array}{l}\text { No.of ships } \\
\text { sailed }\end{array}$ & $\begin{array}{l}\text { Current } \\
\text { rank }\end{array}$ & Education & $\begin{array}{l}\text { Years of sea } \\
\text { service }\end{array}$ & Age & "Confusion" & Fatigue \\
\hline Familiarisation & 0,20 & 0,00 & $-0,07$ & $-0,08$ & 0,05 & 0,18 & $-0,10$ & 0,11 \\
\hline Handover & & 0,32 & $-0,72$ & $-0,13$ & 0,41 & 0,34 & 0,02 & $-0,12$ \\
\hline No.of ships sailed & & & $-0,47$ & $-0,31$ & 0,68 & 0,46 & $-0,16$ & $-0,06$ \\
\hline Current rank & & & & 0,18 & $-0,65$ & $-0,51$ & 0,01 & 0,14 \\
\hline Education & & & & & $-0,31$ & $-0,08$ & 0,08 & 0,15 \\
\hline Years of sea service & & & & & & 0,66 & $-0,08$ & $-0,18$ \\
\hline Age & & & & & & & $-0,09$ & $-0,14$ \\
\hline „Confusion" & & & & & & & & $-0,12$ \\
\hline
\end{tabular}


(Figure 4) indicates that unstandardized equipment could contribute to the prolongation of familiarisation period.

The share of seafarers which have had some type of experience with more than one type of navigational equipment (89 \%) (Figure 5) also shows that problems due to lack of typespecific knowledge could be present.

Similarly, out of $76 \%$ respondents who have had experience with modern IBS, $68 \%$ have been familiarised with more than one type of IBS (Figure 6). These results show that the majority of shipping companies in providing navigational bridges and navigational equipment cooperates with different manufacturers and therefore different workspace and equipment on-board vessels are present. These differences pose an additional problem to seafarers when performing their tasks and could lead to unsafe acts. Therefore, standardisation of important equipment on-board vessels is recommended as a preventive measure. Furthermore, effective deliverance of type-specific training is crucial, taking into account factors which affect learning such as cultural differences, authority gradient and different understanding of technology by users.

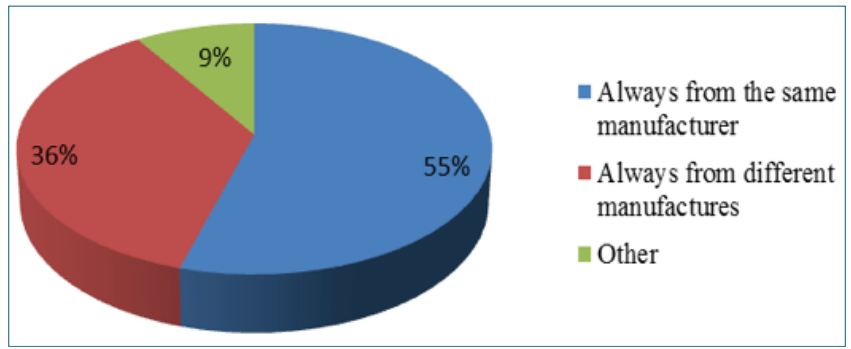

Figure 4.

Answers of respondents about the way companies provide ships with navigational equipment.

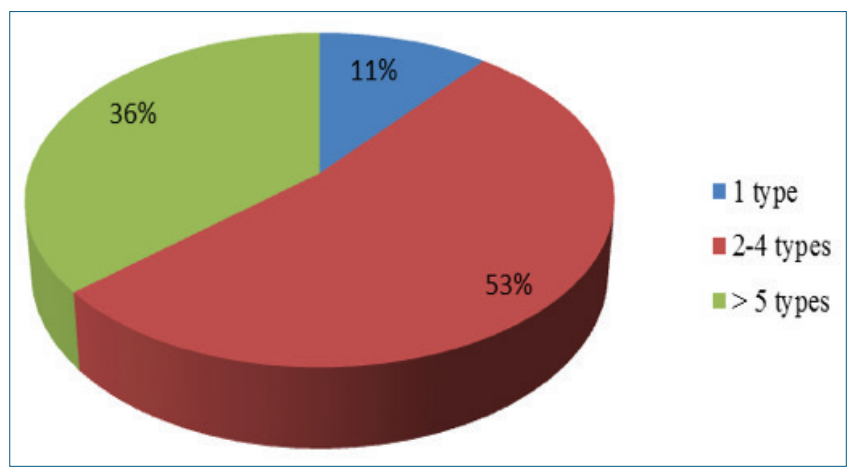

Figure 5.

Answers of respondents on number of navigational equipment (ECDIS, ARPA, AIS) they have had experience with.

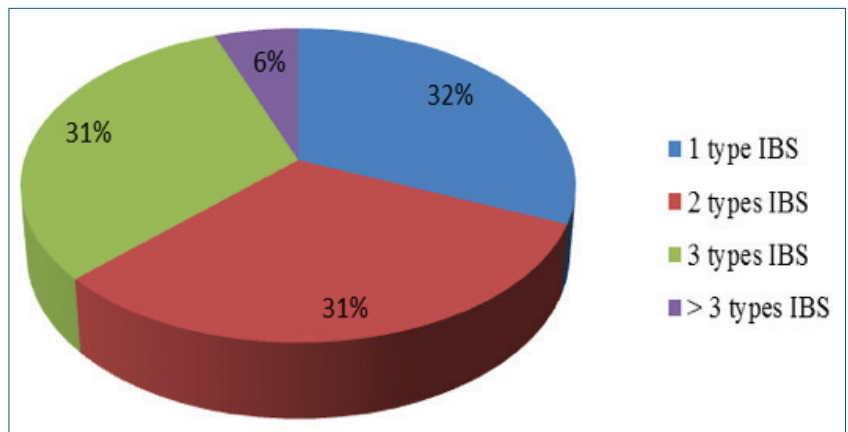

Figure 6.

Answers of respondents on number of types of IBS they have had experience with

According to respondents' answers bridge equipment is maintained on regular basis only in $60 \%$ cases (Figure 7). Considering its role in safe navigation and importance of functioning properly it is potentially a warning data.

The quality of instruction manuals is an important parameter for the evaluation of technology, especially considering the complexity of modern systems and shortage of time available for grasping it (Figure 8). According to the results, the majority

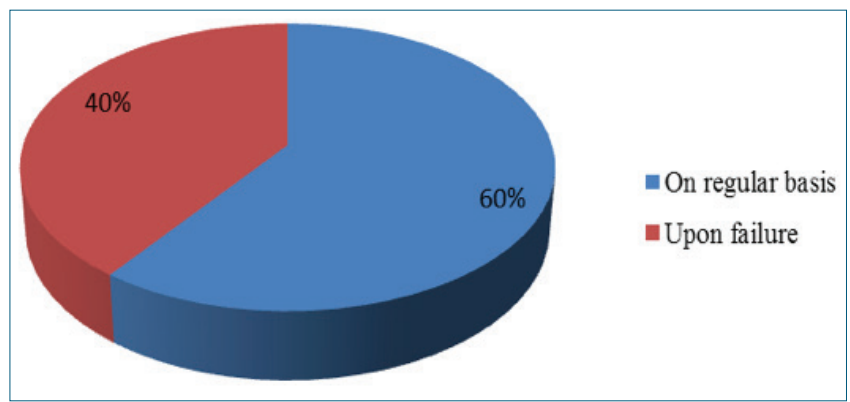

Figure 7.

Answers of respondents about the maintenance procedures of the bridge equipment.

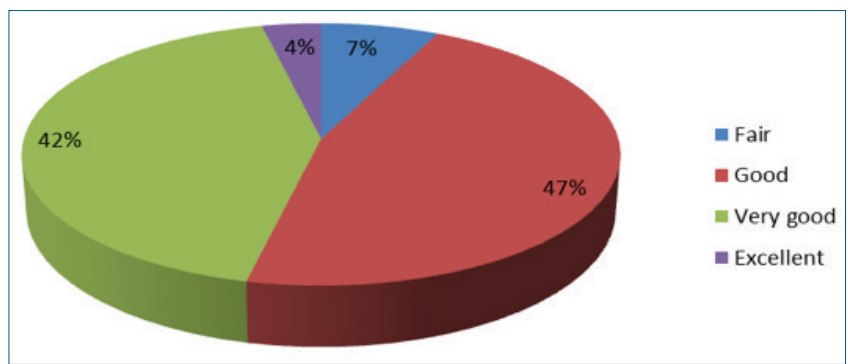

Figure 8.

Respondents' ratings of the instruction manuals of equipment they operated. 
of operators finds the quality of instruction manuals satisfying. Option "very bad" was not selected by the respondents.

Technology acceptance variables, perceived ease of use and usefulness are also significant for safety. Therefore it is important to notice that $27 \%$ respondents have been confused by data on display (Figure 9). The reasons for confusion were small display, too much data, poor graphical display, misunderstanding of alarms, and little time provided for the familiarisation with the system.

An analysis of evaluation of HMI with respect to different variables has shown that there is no statistically significant difference in the evaluation of $\mathrm{HMI}$ with regard to the age of the respondents, length of the sea service, level of education and current position on-board. This result indicates that technology characteristics, not operator capabilities, could be reason for confusion. This is in accordance with findings by Shorrock and Williams (2016) that collaboration between users and designers is essential and that it should be stimulated by all interested stakeholders. For example, reporting equipment deficiencies by operators should be encouraged.

The dominant rating of technology as useful (Figure 10) suggests that seafarers perceive usage of technology as improvement to decision performance and decision processes. However, the fact that $18 \%$ of respondents have answered that they could not work without navigation system indicates

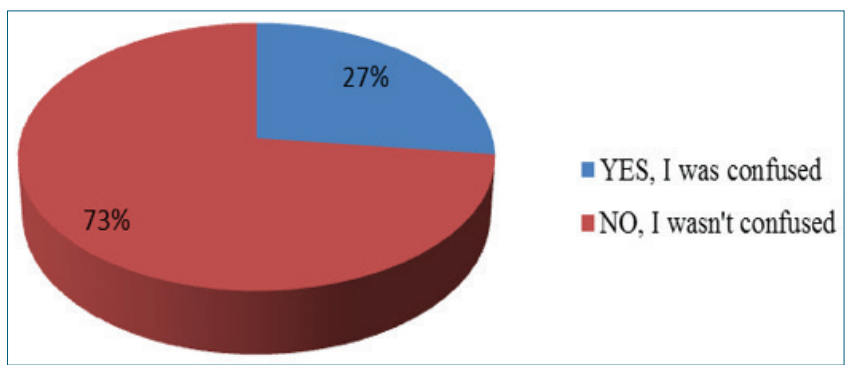

Figure 9.

Answers of respondents whether they have ever been confused by data on the system display.

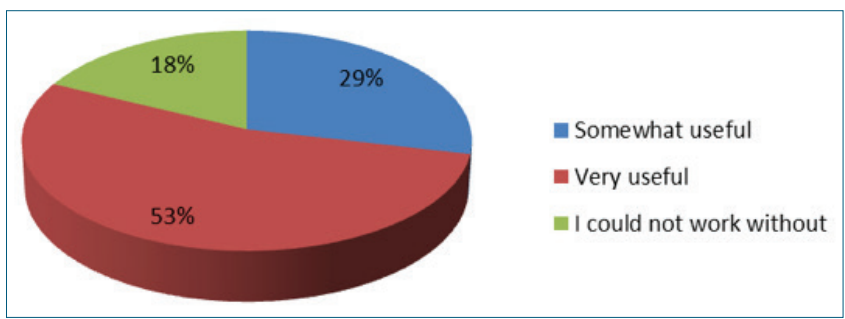

Figure 10.

Answers of respondents on the usefulness of navigation systems during watch. overreliance which could have negative impact on safety. The available options "none" and "not very useful" were not selected by the respondents.

For ship safety it is important to observe that $15 \%$ of respondents always feel fatigued, and $78 \%$ sometimes (Figure 11). According to our analysis (Table 1) fatigue is not connected with the other studied variables, meaning that crew members, regardless of rank and age can exhibit detriment while performing regular duties. There are many possible reasons including inadequate manning, work organisation, time constraints. One of the reasons could be that technological development is not reconciled with the physical capabilities and limitations of operators. The causes of fatigue should be further investigated.

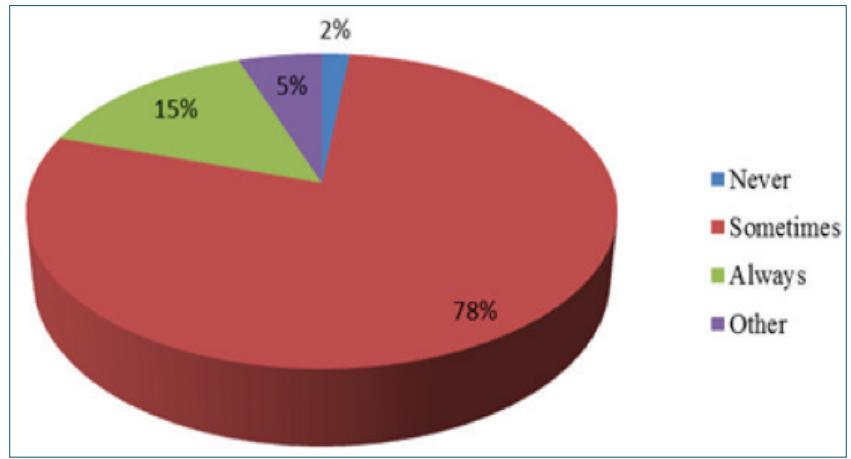

Figure 11.

Answers of respondents on frequency of fatigue while performing their regular tasks on board.

Finally, it should be noted that our results should be interpreted with caution due to the fact that they were obtained with a relatively small sample and should be checked on larger sample, including participants from different cultures. Additionally, there is a potential single source bias. Furthermore, the longitudinal research design is desirable to obtain a proper assessment of the situation. Taking the aforementioned limitations into consideration, this study may present a ground for further research.

\section{CONCLUSION}

Technological processes and level of automation on-board vessels, which have advanced during the last decade, have placed additional requirements for the smaller crew. Along with changes in work organisation, induced by a need for higher efficiency, technology could contribute to the occurrence of human error.

An analysis of marine accidents has revealed a sort of system performance error, and the following factors have been identified: education and experience of the operator, period of familiarisation with navigational equipment, and characteristics of man-machine interface. 
A survey among seafarers, conducted by anonymous questionnaire method, indicates that almost half of respondents encountered a different type of equipment upon embarkation, on the ships of their companies. Also, $40 \%$ of respondents stated that they had met three or more types of integrated navigation bridge during their careers. So many different types of equipment have resulted in almost one third of respondents being confused by the displayed data at some point. The important information is that $40 \%$ of respondents state that navigational equipment is being poorly maintained. Of utmost importance is the fact that half of the respondents stated period of 2-5 days as needed time to adjust to the equipment, in order to be fully prepared to carry out their duties, while the period of handover is substantially shorter.

The results of our study show that present situation, as viewed by ship operators, offers a possibility for dysfunctional interaction between humans and technology. Experiences and attitudes expressed in the survey provide interesting ground for further examination of factors influencing usability of technology. Since quality of this interaction depends on a range of stakeholders (manufacturers, vessel owners, manning companies, regulatory bodies, crew), it is important to understand all issues that can lead to missteps in order to propose comprehensive preventive measures. Therefore, more extended studies on issues related to reducing potential adverse impact of the technology on ship operators are needed. They should include representatives of different stakeholders in order to reduce risk in shipping. If confirmed by further research, our results may have practical implications regarding necessity to involve ship operators in the process of the selection of equipment.

\section{REFERENCES}

Carayon, P., Hancock, P., Leveson, N., Noy, I., Sznelwar, L. and van Hootegem G., (2015), Advancing a Sociotechnical Systems Approach to Workplace Safety Developing the Conceptual Framework. Ergonomics 58(4), pp. 548-564., available at: https://doi.org/10.1080/00140139.2015.1015623

Ćorović, B., and Djurović, P., (2013), Research of Marine Accidents through the Prism of Human Factors, Promet - Traffic \& Transportation 25(4), pp. 369-377., available at: https://doi.org/10.7307/ptt.v25i4.1210

Dhami, H., and Grabowski, M., (2011), Technology impacts on safety and decision making over time in marine transportation, Proceedings of the Institution of Mechanical Engineers, Part O: Journal of Risk and Reliability 225(O3), pp. 269-292., available at:

https://doi.org/10.1177/1748006XJRR359

EMSA (European Maritime Safety Agency) 2015. "Annual Overview of Marine Casualties and Incidents 2015", available at: http://www.emsa.europa.eu/news-apress centre/external-news/item/2551-annual-overview-of-marine-casualties-andincidents-2015.html [accessed 05 May 2017]
Gruhn, P.E., (2011), Human Machine Interface (HMI) Design: The Good, The Bad, and The Ugly (and what makes them so), Paper presented at the 66th Annual Instrumentation Symposium for the Process Industries January 27-29., available at: http://www.kirp.chtf.stuba.sk/moodle/pluginfile.php/61474/mod_resource/ content/2/hmi_rules.pdf [accessed 11 April 2017]

Hetherington, C., R. Flin, and Mearns, K., (2006), Safety in shipping: The human Element, Journal of Safety Research 37(4), pp. 401-411., available at: https://doi.org/10.1016/j.jsr.2006.04.007

IACS (International Association of Classification Societies) 2011. "Rec. 95. Recommendation for the Application of SOLAS Regulation V/15 Bridge Design, Equipment Arrangement and Procedures (BDEAP)-Correction.2" July 2011., available at: http://www.iacs.org.uk/publications/publications.aspx?pageid=4\&sectionid=5, [accessed 17 March 2017]

IACS (International Association of Classification Societies) 2013. "Rec. 132.-Human Element Recommendations for structural design of lighting, ventilation, vibration, noise, access and egress arrangements - New" Dec 2013., available at: http://www. iacs.org.uk/publications/publications.aspx?pageid=4\&sectionid=5, [accessed 17 March 2017]

IMO (International Maritime Organization) 1996. "Resolution, Maritime-SafetyCommittee-(MSC)/ Documents/MSC.64 (67), Annex 17, Page 3, Adoption of new and amended performance standards, 1996".

IMO (International Maritime Organization) 2000a. “SOLAS, International Convention For The Safety Of Life At Sea, 1974, 1988, Protocol Relating Thereto, 2000 Amendments".

IMO (International Maritime Organization) 2000b. “Guidelines on Ergonomic Criteria for Bridge Equipment and Layout module 7, Shipboard Fatigue And The Naval Architect/Ship Designer, MSC/Circ.982" 20. December 2000.

IMO (International Maritime Organization) 2001. "Guidance on Fatigue Mitigation and Management, Annex, Guidelines on Fatigue, Module 7, Shipboard Fatigue And The Naval Architect/Ship Designer, MSC/Circ.1014". 12. June 2001, London

Madden T.J., Hewett, K. and Roth, M.S., (2000), Managing Images in Different Cultures: A Cross-National Study of Color Meanings and Preferences. Journal of International Marketing 8(4), pp. 90-107., available at: https://doi.org/10.1509/jimk.8.4.90.19795

Turan, O., Kurt, R. E., Arslan, V., Silvagni, S., Ducci, M., Liston, P., Schraagen, J. M., Fang, I. and Papadakis, G., (2016), Can we learn from aviation: safety enhancements in transport by achieving human orientated resilient shipping environment, Transportation Research Procedia 14, pp. 1669-1678., https://doi.org/10.1016/j.trpro.2016.05.132

Schröder-Hinrichs, J-U., Hollnagel, E. and Baldauf, M., (2012), From Titanic to Costa Concordia-a century of lessons not learned, WMU Journal of Maritime Affairs 11, pp. 151-167.,

https://doi.org/10.1007/s13437-012-0032-3

Shorrock, S.T. and Williams, C. A., (2016), Human factors and ergonomics methods in practice: three fundamental constraints, Theoretical Issues in Ergonomics Science, 17(5- 6), pp. 468-482.,

https://doi.org/10.1080/1463922X.2016.1155240 